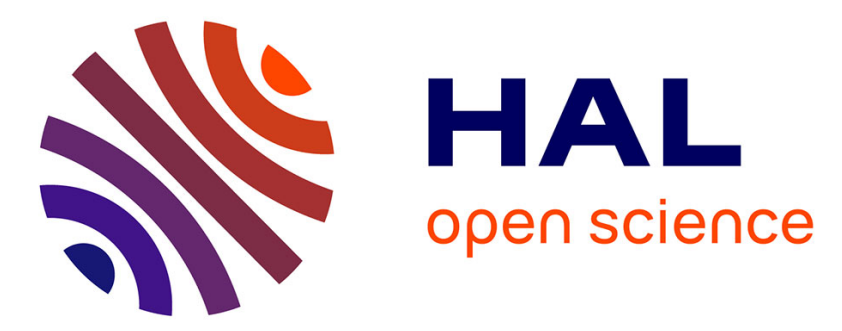

\title{
Surface plasmon resonance imaging coupled to on-chip mass spectrometry: a new tool to probe protein-GAG interactions
}

Cédric Przybylski, Florence Gonnet, Els Saesen, Hugues Lortat-Jacob, Régis Daniel

\section{To cite this version:}

Cédric Przybylski, Florence Gonnet, Els Saesen, Hugues Lortat-Jacob, Régis Daniel. Surface plasmon resonance imaging coupled to on-chip mass spectrometry: a new tool to probe protein-GAG interactions. Analytical and Bioanalytical Chemistry, 2020, 10.1007/s00216-019-02267-2 . hal-02401458

\section{HAL Id: hal-02401458 \\ https://hal-univ-evry.archives-ouvertes.fr/hal-02401458}

Submitted on 20 Dec 2019

HAL is a multi-disciplinary open access archive for the deposit and dissemination of scientific research documents, whether they are published or not. The documents may come from teaching and research institutions in France or abroad, or from public or private research centers.
L'archive ouverte pluridisciplinaire HAL, est destinée au dépôt et à la diffusion de documents scientifiques de niveau recherche, publiés ou non, émanant des établissements d'enseignement et de recherche français ou étrangers, des laboratoires publics ou privés. 


\section{Metadata of the article that will be visualized in OnlineFirst}

\begin{tabular}{|c|c|c|c|}
\hline 1 & Article Title & \multicolumn{2}{|c|}{$\begin{array}{l}\text { Surface plasmon resonance imaging coupled to on-chip mass } \\
\text { spectrometry: a new tool to probe protein-GAG interactions }\end{array}$} \\
\hline 2 & Article Sub- Title & & \\
\hline 3 & $\begin{array}{l}\text { Article Copyright - } \\
\text { Year }\end{array}$ & \multicolumn{2}{|c|}{$\begin{array}{l}\text { Springer-Verlag GmbH Germany, part of Springer Nature } 2019 \\
\text { (This will be the copyright line in the final PDF) }\end{array}$} \\
\hline 4 & Journal Name & \multicolumn{2}{|c|}{ Analytical and Bioanalytical Chemistry } \\
\hline 5 & \multirow{14}{*}{$\begin{array}{l}\text { Corresponding } \\
\text { Author }\end{array}$} & Family Name & Przybylski \\
\hline 6 & & Particle & \\
\hline 7 & & Given Name & Cédric \\
\hline 8 & & Suffix & \\
\hline 9 & & Organization & Université Paris-Saclay, CNRS, Université Evry \\
\hline 10 & & Division & $\begin{array}{l}\text { Laboratoire Analyse et Modélisation pour la Biologie et } \\
\text { l'Environnement }\end{array}$ \\
\hline 11 & & Address & Evry 91025, France \\
\hline 12 & & Organization & Sorbonne Université, CNRS \\
\hline 13 & & Division & Institut Parisien de Chimie Moléculaire, IPCM \\
\hline 14 & & Address & 4 Place Jussieu, Paris Cedex 05 75252, France \\
\hline 15 & & Organization & Sorbonne Université, CNRS \\
\hline 16 & & Division & Institut Parisien de Chimie Moléculaire, IPCM \\
\hline 17 & & Address & 4 Place Jussieu, Paris Cedex 05 75252, France \\
\hline 18 & & e-mail & cedric.przybylski@sorbonne-universite.fr \\
\hline 19 & \multirow{8}{*}{$\begin{array}{l}\text { Corresponding } \\
\text { Author }\end{array}$} & Family Name & Daniel \\
\hline 20 & & Particle & \\
\hline 21 & & Given Name & Régis \\
\hline 22 & & Suffix & \\
\hline 23 & & Organization & Université Paris-Saclay, CNRS, Université Evry \\
\hline 24 & & Division & $\begin{array}{l}\text { Laboratoire Analyse et Modélisation pour la Biologie et } \\
\text { l'Environnement }\end{array}$ \\
\hline 25 & & Address & Evry 91025 , France \\
\hline 26 & & e-mail & regis.daniel@univ-evry.fr \\
\hline 27 & \multirow{3}{*}{ Author } & Family Name & Gonnet \\
\hline 28 & & Particle & \\
\hline 29 & & Given Name & Florence \\
\hline
\end{tabular}


30

31

32

33

34

35

36

37

38

39

40

41

42

43

44

45

46

47

48

49

50

51

52 Schedule

53

54

Author

Author

Abstract
Suffix

Organization

Division

Address

e-mail

Family Name Saesen

Particle

Given Name

Els

Suffix

Organization Université Grenoble Alpes, CNRS, CEA

Division

Institut de Biologie Structurale

Address

Grenoble 38000, France

e-mail

\section{Family Name}

Lortat-Jacob

Particle

Given Name

Hugues

Suffix

Organization

Université Grenoble Alpes, CNRS, CEA

Division

Institut de Biologie Structurale

Address

Grenoble 38000, France

e-mail

Received

9 September 2019

Revised

11 October 2019

Accepted

8 November 2019

Biosensor device for the detection and characterization of proteinglycosaminoglycan interactions is being actively sought and constitutes the key to identifying specific carbohydrate ligands, an important issue in glycoscience. Mass spectrometry (MS) hyphenated methods are promising approaches for carbohydrates enrichment and subsequent structural characterization. In the study herein, we report the analysis of interactions between the glycosaminoglycans (GAGs) heparin (HP) and heparan sulfate (HS) and various cytokines by coupling surface plasmon resonance imaging (SPRi) for thermodynamic analysis method and MALDI-TOF MS for structural determination. To do so, we developed an SPR biochip in a microarray format and functionalized it with a selfassembled monolayer of short poly(ethylene oxide) chains for grafting the human cytokines stromal cell-derived factor-1 (SDF-1 $\alpha$ ), monocyte chemotactic protein-1 (MCP-1), and interferon- $\gamma$. The thermodynamic parameters of the interactions between these cytokines and unfractionated HP/HS and derived oligosaccharides were successively determined using SPRi monitoring, and the identification of the captured carbohydrates was carried out directly on the biochip surface using MALDI-TOF MS, revealing cytokine preferential affinity for GAGs. The MS 
identification was enhanced by on-chip digestion of the cytokine-bound GAGs with heparinase, leading to the detection of oligosaccharides likely involved in the binding sequence of GAG ligands. Although several carbohydrate array-based assays have been reported, this study is the first report of the successful analysis of protein-GAG interactions using SPRi-MS coupling.

\begin{tabular}{|c|c|c|}
\hline & $\begin{array}{l}\text { Keywords separated } \\
\text { by ' - ' }\end{array}$ & $\begin{array}{l}\text { SPR-MS - Glycosaminoglycans - Surface plasmon resonance - Mass } \\
\text { spectrometry - Cytokines - Heparin }\end{array}$ \\
\hline & $\begin{array}{l}\text { Foot note } \\
\text { information }\end{array}$ & $\begin{array}{l}\text { The online version of this article (https://doi.org/ } 10.1007 \\
\text { /s00216-019-02267-2) contains supplementary material, which is availat } \\
\text { authorized users. }\end{array}$ \\
\hline
\end{tabular}

\section{Electronic s upplementary material}

ESM 1

(PDF $239 \mathrm{~kb}$ ) 


\title{
Surface plasmon resonance imaging coupled to on-chip mass spectrometry: a new tool to probe protein-GAG interactions
} \\ Received: 9 September 2019 / Revised: 11 October 2019 / Accepted: 8 November 2019 \\ (C) Springer-Verlag GmbH Germany, part of Springer Nature 2019
}

\begin{abstract}
Biosensor device for the detection and characterization of protein-glycosaminoglycan interactions is being actively sought and constitutes the key to identifying specific carbohydrate ligands, an important issue in glycoscience. Mass spectrometry (MS) hyphenated methods are promising approaches for carbohydrates enrichment and subsequent structural characterization. In the study herein, we report the analysis of interactions between the glycosaminoglycans (GAGs) heparin (HP) and heparan sulfate (HS) and various cytokines by coupling surface plasmon resonance imaging (SPRi) for thermodynamic analysis method and MALDI-TOF MS for structural determination. To do so, we developed an SPR biochip in a microarray format and functionalized it with a self-assembled monolayer of short poly(ethylene oxide) chains for grafting the human cytokines stromal cell-derived factor-1 (SDF-1 $\alpha$ ), monocyte chemotactic protein-1 (MCP-1), and interferon- $\gamma$. The thermodynamic parameters of the interactions between these cytokines and unfractionated HP/HS and derived oligosaccharides were successively determined using SPRi monitoring, and the identification of the captured carbohydrates was carried out directly on the biochip surface using MALDI-TOF MS, revealing cytokine preferential affinity for GAGs. The MS identification was enhanced by on-chip digestion of the cytokine-bound GAGs with heparinase, leading to the detection of oligosaccharides likely involved in the binding sequence of GAG ligands. Although several carbohydrate array-based assays have been reported, this study is the first report of the successful analysis of protein-GAG interactions using SPRi-MS coupling.
\end{abstract}

Keywords SPR-MS · Glycosaminoglycans $\cdot$ Surface plasmon resonance $\cdot$ Mass spectrometry $\cdot$ Cytokines $\cdot$ Heparin

\section{Introduction}

Glycosaminoglycans (GAGs) are sulfated polysaccharides found in the extracellular matrix and at the cell surface where

Electronic supplementary material The online version of this article (https://doi.org/10.1007/s00216-019-02267-2) contains supplementary material, which is available to authorized users.

Cédric Przybylski

cedric.przybylski@sorbonne-universite.fr

Régis Daniel

regis.daniel@univ-evry.fr

1 Laboratoire Analyse et Modélisation pour la Biologie et l'Environnement, Université Paris-Saclay, CNRS, Université Evry, 91025 Evry, France

2 Present address: Institut Parisien de Chimie Moléculaire, IPCM, Sorbonne Université, CNRS, 4 Place Jussieu, 75252 Paris Cedex 05, France

3 Institut de Biologie Structurale, Université Grenoble Alpes, CNRS, CEA, 38000 Grenoble, France they are anchored to a protein core and constitute the proteoglycans assemblies [1]. They mediate cell-cell and cell-matrix interactions involved in a variety of physiological and pathological functions such as in embryonic development, cell growth and differentiation, homeostasis, inflammatory response, tumor growth, and microbial infection [1-3]. Most of these GAG functions are mediated by the binding to protein effectors such as growth factors and cytokines whose biological activities are in turn regulated by modulating their availability, stability, structure, and reactivity [3-7]. These proteinGAG interactions are driven at an electrostatic level by the overall sulfation of the GAG chains $[4,8]$, and also by the specific recognition of structural determinants, especially the arrangement of the $\mathrm{N}$ - and $\mathrm{O}$-sulfo groups in a given oligosaccharide sequence, as observed in heparan sulfate (HS) [4, 9-12]. These structural elements give rise to the so-called sulfate code that remains to be cracked [13-15]. Other features, such as epimerization and distribution of sulfated domains along the GAG chains, are also involved [10, 16-22].

Therefore, the study of non-covalent protein-GAG complexes has raised increasing interest with the aim of 
determining the structure of the carbohydrate ligand and designing GAG-like drugs targeting these complexes for potential therapeutic applications [23, 24]. However, the large structural diversity of GAGs owing to their incomparable variety of combinations and regioselective modifications of their constitutive monosaccharides represents a major stumbling block in the study of structure-activity relationships [25]. Furthermore, the biologically active GAG sequences involved in molecular recognition are most often available in low amounts and in heterogeneous mixtures. Because GAG biosynthesis is not template-driven, no procedure is available for the amplification and the over-expression of a specific oligosaccharide sequence [3]. Therefore, deciphering the mechanism of the protein-GAG interactions and structural identification of the carbohydrate ligands is both a major scientific goal and a tremendous analytical challenge. In response to the aforementioned bottlenecks, significant progress has been made during the last decade by using mass spectrometry (MS) and MS hyphenated methods, which offer highly sensitive detection and powerful structural resolution $[26,27]$. We have previously reported the coupling between affinity capillary electrophoresis to mass spectrometry (ACE-MS) as an efficient method for probing protein-GAG interaction [28, 29]. ACE-MS coupling offers the advantage of requiring a minimal amount of sample for analysis, a definite benefit owing to the low bioavailability of GAG samples. Nevertheless, ACE does not allow multiplexed parallel measurement of interactions, a major goal in the current "omics" era. In 2002, glycan array approaches were introduced to develop the high-throughput detection of carbohydrate ligands [30-32]. Unlike glycan arrays, surface plasmon resonance (SPR) can probe biomolecular interactions at the thermodynamic level and offers the advantages of real-time and label-free measurement of reaction rate constants $\left(\mathrm{k}_{\mathrm{on}}, \mathrm{k}_{\mathrm{off}}\right)$ from which equilibrium constants $\left(\mathrm{K}_{\mathrm{A}}, \mathrm{K}_{\mathrm{D}}\right)$ can be deduced [33]. Furthermore, following the pioneering works of Nelson et al. [34, 35], the recent introduction of SPR in array format provides access to a multiplexed analysis that is of great interest for "omics" approaches, but unfortunately does not give structural information on the captured ligand(s). In this context, we and others have recently reported the hyphenation of SPR imaging (SPRi) on a biochip in an array format compatible with MS detection [36-38]. The hyphenation of SPRi with MS relies on two well-established stand-alone methods for the analysis of biomolecular interactions and biostructural characterization, respectively. We have introduced an SPR sensor biochip in a microarray format that is easily interfaced with a MALDI mass spectrometer to carry out a direct on-chip structural analysis by MS. The coupling relies on the functionalization of the biochip surface by a self-assembled monolayer of short poly(ethylene oxide) chains, which-unlike the commonly used alkane thiol chains - greatly minimize non-specific binding and improve selective isolation and MS detection on the
SPR biochip, even for complex biological matrices such as biological fluids [39]. Using this experimental set-up, we previously carried out SPRi-MS coupling for probing proteinprotein interactions [36, 37]. Affinity-based enrichment and isolation of specific ligands on the SPR biosensor combined with their structural identification by MS also appears a particularly welcome and innovative coupling in glycomics field. Therefore, in the study herein, we have investigated the potential of SPRi-MS coupling for the detection and analysis of protein-GAG interactions. To do so, we designed an SPR sensor biochip arrayed with multiple cytokines, providing access to the thermodynamics parameters of their interactions with HS, heparin (HP) and HP oligosaccharides. This cytokine biochip was conveniently interfaced with a MALDI-TOF mass spectrometer so as to achieve a first step towards the structural identification of the captured sulfated GAG ligands.

\section{Experimental}

\section{Materials and reagents}

O-(2-Carboxyethyl)-O'-(2-mercaptoethyl) heptaethylene glycol (PEO), N,N'-dicyclohexylcarbodiimide (DCC), 4pyrrolidinopyridine, N-hydroxysuccinimide (NHS), ammonium acetate, sodium chloride, L-lysine, dimethyl sulfoxide (DMSO), ammonium acetate, 2-(4-hydroxy-phenylazo) benzoic acid (HABA), and 1,1,3,3, tetramethylguanidine (TMG) were purchased from Sigma-Aldrich (Saint-Quentin Fallavier, France). Heparin (HP, $\approx 16,000 \mathrm{~g} \mathrm{~mol}^{-1}$ ) and heparan sulfate $\left(\mathrm{HS}, \approx 13,634 \mathrm{~g} \mathrm{~mol}^{-1}\right.$ ) were purchased from Celsus Laboratories Inc. (Cincinnati, OH, USA). A mixture of heparin decasaccharides (HPdp10) was purchased from Dextra Laboratories (Reading, UK). Synthetic heparin pentasaccharide Fondaparinux was a gift from Sanofi (France). Aprotinin (average Mw $6517.5375 \mathrm{~g} \mathrm{~mol}^{-1}$ ) was purchased from Sigma-Aldrich. Lyophilized recombinant human stromal cell-derived factor-1 (SDF-1 $\alpha$, residue 1-68, average Mw $7959.3999 \mathrm{~g} \mathrm{~mol}^{-1}$, purity $\geq 98 \%$ ) and recombinant human monocyte chemotactic protein-1 (MCP-1, residue 1-76, average Mw $8680.9987 \mathrm{~g} \mathrm{~mol}^{-1}$, purity $\geq 98 \%$ ) were obtained from PeproTech (Neuilly-sur-Seine, France). Recombinant interferon- $\gamma$ (IFN- $\gamma$, residue 1-144, average Mw $16,907.3451 \mathrm{~g} \mathrm{~mol}^{-1}$ ) in $10 \mathrm{mM}$ Tris buffer $\mathrm{pH} 6.8$ containing $10 \mathrm{mg} \mathrm{mL}^{-1}$ mannitol was produced as described elsewhere [40]. Other chemicals and reagents were obtained from commercial sources at the highest purity available. All buffers were prepared using ultrapure water (Milli-Q, Millipore, Milford, MA, USA). All heparin lyases (heparinases I, II,

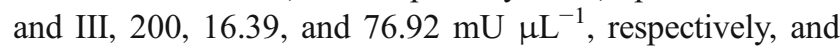
conditioned in $0.2 \%$ bovine serum albumin) were purchased form Grampian Enzymes (Aberdeen, Scotland, UK). 


\section{Working protein solutions}

Commercial solutions of heparinases I, II, and III were diluted at $5 \mathrm{mU} \mu \mathrm{L}^{-1}, 4.09 \mathrm{mU} \mu \mathrm{L}^{-1}$, and $3.125 \mathrm{mU}_{\mu} \mathrm{L}^{-1}$, respectively, in $20 \mathrm{mM}$ Tris-HCl, $\mathrm{pH} 7.2$, and stored at $-80^{\circ} \mathrm{C}$ until use. Just prior to digestion, heparinase I was diluted to $100 \mathrm{mU} \mathrm{mL}^{-1}$ ), and heparinases II and III to $50 \mathrm{mU} \mathrm{mL}^{-1}$ in $2 \mathrm{mM}$ PBS, $0.6 \mathrm{mM} \mathrm{CaCl}_{2}, \mathrm{pH}$ 7.3. Aprotinin, SDF- $1 \alpha$, MCP-1, and IFN- $\gamma$ were diluted to $75 \mu \mathrm{M}$ in $75 \mathrm{mM}$ ammonium acetate, $\mathrm{pH} 6.5,3 \mu \mathrm{L}$ (aprotinin, SDF-1 $\alpha$, MCP-1) or $5 \mu \mathrm{L}(\mathrm{IFN}-\gamma)$ aliquots were stored at $-80{ }^{\circ} \mathrm{C}$ until use.

\section{SPRi instrument}

SPR imaging (SPRi) experiments were performed using the SPRi-Plex imager (instrument control and reporting by SPRi-View and SPRi-Analysis software suite, Horiba Scientific, Palaiseau, France) equipped with a $660-\mathrm{nm}$ light-emitting diode (LED), a hexagonal flow cell thermostated at $25^{\circ} \mathrm{C}$, an online degasser, and a chargecoupled-device (CCD) camera. SPRi measurements were performed using gold-covered glass slides $(28 \mathrm{~mm} \times$ $12 \mathrm{~mm}, 0.5-\mathrm{mm}$ thickness, chromium bonding layer 1$2 \mathrm{~nm}$, gold layer $50 \mathrm{~nm}$ ) purchased from SCHOTT-AG (Mainz, Germany) assembled onto a glass prism (thickness $8 \mathrm{~mm}$ ) from Horiba Scientific (Palaiseau, France). The optical continuity at their interface was ensured by an oil layer of suitable refractive index, as described elsewhere [36].

\section{SPRi and SPRi-MS coupling experiments}

SPRi experiments were performed in the running buffer $10 \mathrm{mmol} \mathrm{L}^{-1}$ ammonium acetate, $\mathrm{pH} 7.5$, at $50 \mu \mathrm{L} \mathrm{min}^{-1}$ flow rate. A typical SPR experiment comprised an injection step (4 min) and a dissociation step (4 min) run sequentially for a total run-time of $8 \mathrm{~min}$. A regeneration step was carried out by injection of $1 \mathrm{~mol} \mathrm{~L}^{-1} \mathrm{NaCl}$ for 8 min between each SPRi experiment. This procedure enabled repeated (at least 20 times) SPR experiments on the same biochip with signal loss of $<3 \%$. For SPRi-MS coupling experiments, the biochip was removed from the glass prism after SPRi measurements to enable direct on-chip MS analysis (see below). The polysaccharides HP, HS, and oligosaccharides HPdp10 and Fondaparinux were injected using a $200-\mu \mathrm{L}$ sample loop injection. They were diluted in the running buffer from 1 to 1000 or $1176 \mu \mathrm{g} \mathrm{mL}^{-1}$ for HP and HS, respectively and from $1 \mathrm{fg} \mathrm{mL}^{-1}$ to $1 \mathrm{mg} \mathrm{mL}^{-1}$ and $1 \mathrm{pg} \mathrm{mL}^{-1}$ to $1 \mathrm{mg} \mathrm{mL}^{-1}$ for HPdp10 and Fondaparinux, respectively. Affinity constants and kinetics rate were determined by using ScrubberGen software (V1.0, Horiba Scientific, Palaiseau, France).
Surface functionalization of biochips

The biochip surface was cleaned using a UV-ozone treatment (UVO-Cleaner, Jelight, CA, USA) before functionalization. A self-assembled monolayer (SAM) formed of a short poly(ethylene oxide) chains was grafted on the gold surface of the biochips by immersion in ethanol solution of $2.5 \mathrm{mmol} \mathrm{L}^{-1}$ O-(2-carboxyethyl)-O'-(2-mercaptoethyl) heptaethylene glycol for $6 \mathrm{~h}$. The grafted biochips were then washed with ethanol and could be either stored at $4{ }^{\circ} \mathrm{C}$ or activated for the immobilization of protein probes. The SAM was activated through $1 \mathrm{~h}$ incubation with $0.2 \mathrm{~mol} \mathrm{~L}^{-1} \mathrm{DCC}$ and $0.2 \mathrm{~mol} \mathrm{~L}^{-1} \mathrm{NHS}$ in DMSO containing $0.02 \mathrm{~mol} \mathrm{~L}^{-1} 4$ pyrrolidinopyridine. After washing with DMSO and ultrapure water, the activated biochips were air-dried and stored at $4{ }^{\circ} \mathrm{C}$, ready for the covalent attachment of chemokines.

\section{Cytokine attachment on biochips}

199

200

201

202

203

204

205

206

207

208

209

210

211

212

Before immobilization on the biochip, the $75 \mu \mathrm{M}$ chemokine solution in $75 \mathrm{mM}$ ammonium acetate, $\mathrm{pH} 6.5$ was evaporated and re-suspended in the same volume of $10 \mathrm{mM}$ ammonium acetate $\mathrm{pH} 7.5,1 \%(\mathrm{v} / \mathrm{v})$ glycerol. The activated biochip was then arrayed with this $75 \mu \mathrm{M}$ chemokine solution by dropping $0.1-0.15 \mu \mathrm{L}$ per spot. The spot-array pattern $(4 \times 4)$ was $500-\mu \mathrm{m}$ diameter spots with a $3.5-\mathrm{mm}$ inter-spot distance. Inactivation of the remaining free ester active groups on the biochip surface was performed by injecting $100 \mu \mathrm{M}$ lysine in $10 \mathrm{mM}$ ammonium acetate, $\mathrm{pH} 7.5$, for $2 \times 10 \mathrm{~min}$

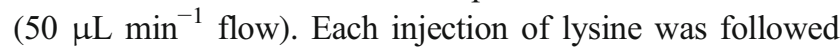
by an injection of $100 \mu \mathrm{M}$ glycine, $\mathrm{pH} 2$ at a $50 \mu \mathrm{L} \mathrm{min}{ }^{-1}$ flow rate for $10 \mathrm{~min}$. Reflectivity variation (RV) was measured on each spot and converted into bound ligand quantities per surface unit $\left(0.02 \%\right.$ of $\mathrm{RV}=5 \mathrm{pg} / \mathrm{mm}^{2}$ [41]. Nevertheless, obtained values were for protein/DNA according to equation S1 (Electronic Supplementary Material (ESM)), whereas the heparin-based saccharides studied here required a lower refractive index (0.13 instead of 0.19$)$. The values of bound amounts were corrected accordingly (\% of RV $\times 1.46)$ [42]. The density values were averaged over all spots of the same species, after subtraction of a negative control. Sensorgrams were acquired on each cytokine spot by subtraction of the SPR signal recorded on the lysine passivated biochip surface. A constant spot diameter of $300 \mu \mathrm{m}$ was used for captured amount calculation.

\section{On-chip digestion}

After SPRi detection and GAG capture, the SPRi biochip was removed from the SPRi-Plex imager and the gold surface was air-dried. Then, on-chip depolymerization of affinity-captured GAG polysaccharides was performed by dropping heparinase solutions on each spot. HP depolymerization was carried out 
with $0.5 \mu \mathrm{L}$ of heparinase I working solution ( $50 \mu \mathrm{U}$ spotted). HS depolymerization was carried out with $0.2 \mu \mathrm{L}$ of heparinase I working solution ( $20 \mu \mathrm{U}$ spotted) and $0.4 \mu \mathrm{L}$ of heparinase II and III working solutions (each $20 \mu \mathrm{U}$ spotted). Then, the on-chip depolymerization reaction was conducted at $25^{\circ} \mathrm{C}$ overnight by arranging the biochip in a Petri dish with a plastic cup to maintain a moist environment, and placed in a forced air oven.

\section{On-chip mass spectrometry analysis}

MALDI-time-of-flight (TOF) MS experiments were performed using a PerSeptive Biosystems Voyager-DE STR mass spectrometer (Applied Biosystems/MDS SCIEX, Foster City, CA, USA) equipped with a nitrogen laser (337 nm wavelength and $20 \mathrm{~Hz}$ repetition rate, laser fluence set just above the desorption/ionization threshold). The $\mathrm{HABA} / \mathrm{TMG}_{2}$ ionic liquid, used as the matrix, was prepared as described elsewhere [43-45]. Briefly, HABA was mixed with TMG at a 1:2 molar ratio in methanol, and the obtained solution was sonicated for $15 \mathrm{~min}$ at $40{ }^{\circ} \mathrm{C}$. After removing methanol by centrifugal evaporation in a SpeedVac for $3 \mathrm{~h}$ at room temperature, the ionic liquid matrix was left under vacuum overnight. Final solutions were then prepared at a concentration of $90 \mathrm{mg} \mathrm{mL}^{-1}$ in methanol, and used as a matrix without further purification. Once prepared, these ionic liquid matrix solutions (ILMs) can be stored at $4{ }^{\circ} \mathrm{C}$ for up to 1 week. Then, $0.4 \mu \mathrm{L}$ of the ILM was spotted on the biochip and left to dry at room temperature and atmospheric pressure for $5 \mathrm{~min}$. MALDI-TOF MS analysis was performed in the linear and reflector negative ion modes. In linear mode, the acceleration voltage was $+25 \mathrm{kV}$, grid voltage was $95 \%$, and extraction delay was $300 \mathrm{~ns}$. In reflector mode, the acceleration voltage was $+20 \mathrm{kV}$, grid voltage was $70 \%$, and extraction delay was 150-300 ns. Each mass spectrum was an average of 200-900 laser shots.

\section{Results and discussion}

\section{MS detection of heparin and heparan sulfate on cytokine surface plasmon resonance biochips}

We previously implemented functionalized SPR biochips to hyphenate SPRi analysis with mass spectrometry [36, 37]. This innovative SPRi-MS coupling can be combined with on-chip enzyme digestion of the captured biomolecule to attain fine structural characterization using MS. Unfractionated HP and HS solutions ranging from sub-nanomolar to micromolar concentrations were flowed on the SPR biochip designed for MS coupling and arrayed with the cytokines IFN- $\gamma$, SDF- $1 \alpha$. Because these cytokines are basic proteins (pI>9) $[28,46]$, aprotinin (pI 10.5) was also grafted on the biochip as a control basic protein. Typical sensorgrams were obtained, showing strong interactions of IFN $-\gamma$ and SDF- $1 \alpha$ with both sulfated polysaccharides (Fig. 1), while the negative control aprotinin showed a weak interaction $\left(\mathrm{K}_{\mathrm{D}}=873 \pm\right.$ $30 \mu \mathrm{M}$ ), consistent with the HP-binding properties of these cytokines. $K_{D}$ values $\left(K_{D}=k_{\text {off }} / k_{\text {on }}\right)$ were determined in the nanomolar range for both cytokines (Table 1), corroborating data in the literature for IFN- $\gamma(1.4-5 \mathrm{nM})[8,47]$ and for SDF-1 $\alpha(1-30 \mathrm{nM})$ [48-50]. The affinity of IFN- $\gamma$ and SDF-1 $\alpha$ was slightly higher for HS than for HP (Table 1), despite the higher sulfate content of HP, indicating that interaction is not solely charge driven. The interaction likely involves specific sequences within HS, keeping in mind that HS is a physiological ligand of cytokines at the cell surface and in the extracellular matrix. In order to determine the GAG molecules captured on the biochip surface, the arrayed surface of the cytokine biochip was probed using MALDI-TOF MS after the SPR experiment.

However, due to their high and disperse molecular weights and negative charge density, the whole HP and HS molecules (13.6-16 $\mathrm{kg} \mathrm{mol}^{-1}$ ) cannot be analyzed as such by MS. To overcome such limitations, we performed on-chip depolymerization of captured GAGs using heparinase I or a mixture of heparinase I, II, and III (see "Methods"). Afterwards, the chip was directly analyzed using MALDI-TOF MS to carry out onchip detection of the oligosaccharides produced by enzyme digestion. The capture of GAG molecules by the grafted cytokines IFN- $\gamma$ and SDF- $1 \alpha$ increased with the increasing concentrations of HP and HS loaded on the chip during the SPR experiment, reaching a maximal surface density of several $\mathrm{fmol} / \mathrm{mm}^{2}$ for both HP and HS (Fig. 2).

Considering that $1 \mathrm{~mol}$ of HP polysaccharide can theoretically yield on average 25 mol of trisulfated HPdp2 based on the molecular weight of the full-size heparin, it is expected that the amount of captured HS is enough to produce several dozen of $\mathrm{fmol} / \mathrm{mm}^{2}$ of sulfated disaccharides. MALDI-TOF-MS analysis revealed the presence of heparin hexa-, tetra-, and disaccharides captured on IFN- $\gamma$ spots. No oligosaccharide was detected on the surface biochip without grafted cytokines (background area, ESM Fig. S1). The HP disaccharide was detected in its fully trisulfated form (sodiated ions $[\mathrm{M}-\mathrm{Na}]^{-}$at $\mathrm{m} / \mathrm{z}, 641.91$ and $[\mathrm{M}-2 \mathrm{Na}+\mathrm{H}]^{-}$at $\mathrm{m} / z$ 619.91) (Fig. 3a, b). The disulfated disaccharide was also detected as $[\mathrm{M}-\mathrm{Na}]^{-}$at $m / z 539.96$ and at trace amounts as $[\mathrm{M}-2 \mathrm{Na}+\mathrm{H}]^{-}$at $\mathrm{m} / \mathrm{z} 517.98$. The fully sulfated $\mathrm{HP}$ tetrasaccharide was identified at $\mathrm{m} / z, 1306.64[\mathrm{M}-\mathrm{Na}]^{-}$, as well as the penta- and tetrasulfated forms at $\mathrm{m} / \mathrm{z} 1204.72$ and 1102.81, respectively. Hexasaccharides were the highest detected dp under the fully sulfated form (9 sulfate groups) as [M-Na] $]^{-}$at $\mathrm{m} / \mathrm{z}$ 1971.55, as well as with 8 and 7 sulfate groups at $m / z 1869.63$ and 1767.71, respectively. Regarding the aprotinin spot, a unique peak of trisulfated HPdp2 was present (Fig. 3c). Some minor ions showing $\mathrm{Na}^{+} / \mathrm{K}^{+}$exchanges were also detected. The control experiment in which digested heparin was manually spotted on a 
Fig. 1 Surface-subtracted sensorgrams for the interaction between cytokines and a heparin injected at $1 \mathrm{mg} \mathrm{mL}^{-1}(\approx$ $73.5 \mu \mathrm{M})$ or $\mathbf{c}$ heparan sulfate injected at $1 \mathrm{mg} \mathrm{mL}^{-1}(\approx$ $73.4 \mu \mathrm{M})$. Each sensorgram is an average of SPR measurements taken on four spots. Corresponding real-time array imaging of the interaction between grafted chemokines and injected $\mathbf{b}$ heparin and $\mathbf{d}$ heparan sulfate at $7 \mathrm{~min}$ in the aforementioned conditions
SPRi biochip without grafted cytokines, yielded mainly trisulfated disaccharides (ESM Fig. S2). This result suggests that the tetra- and hexasaccharides detected on the cytokine plots are protected from heparinase through tight protein-GAG interactions. These oligosaccharides may thus be part of the heparin sequences that are specifically involved in the cytokine binding (Fig. 3). In contrast, we were unable to detect highly sulfated diand tetra-oligosaccharides from HS molecules captured on IFN- $\gamma$ and SDF- $1 \alpha$ spots. Although somewhat lower than the captured HP level, the amount of captured HS was still sufficient to allow MS detection of derived oligosaccharides.

Heparinase I exhibits a strong specificity for the -GlcNS6SIdoA2S- linkage [51]. This saccharide sequence being less encountered in HS, the on-chip depolymerization of HS a

C

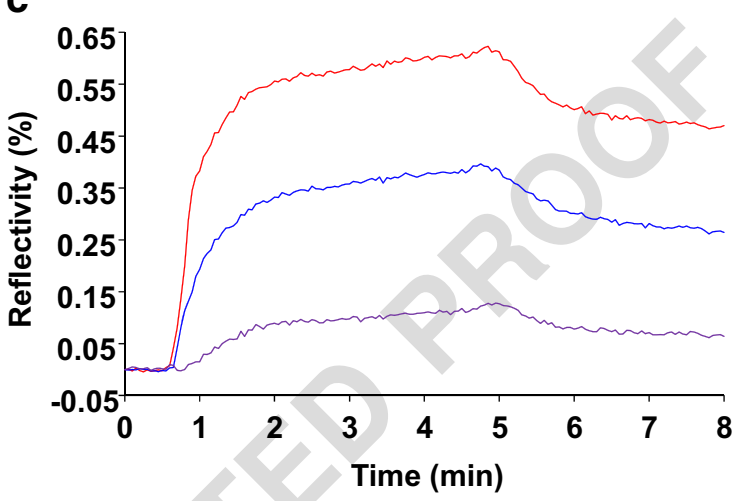

IFN-Y

SDF-1 $\alpha$ b

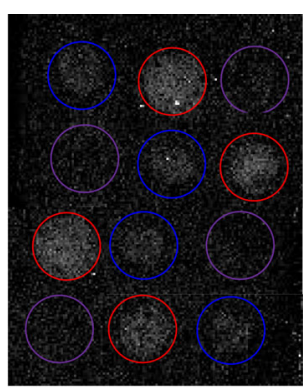

d

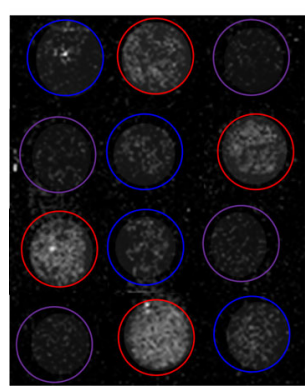

Aprotinin molecules catalyzed by heparinase I likely produced a lower proportion of highly sulfated di- and tetra-saccharides, and a higher proportion of longer oligosaccharides that are more difficult to detect by MS.

\section{Direct on-chip MS detection of heparin oligosaccharide ligands}

The SPR-MS experiment was further pursued by loading HP decasaccharides (HPdp10) on a cytokine biochip. Given that this commercial HPdp10 preparation was specified to contain a high level of the disaccharide unit IdoUA,2S-GlcNS,6S, it may be a valuable mimic of the sulfated NS domains of HS (the so-called NS domains), which are well known to be

Table 1 Kinetic and thermodynamic parameters of the interactions between cytokines and heparin (HP)/heparan sulfate (HS) glycosaminoglycans (GAGs)

\begin{tabular}{|c|c|c|c|c|c|c|}
\hline GAGs & Cytokine & $\begin{array}{l}\text { Surface density } \\
\left(\text { fmol } \mathrm{mm}^{-2}\right)\end{array}$ & $\mathrm{k}_{\mathrm{on}}\left(\mathrm{M}^{-1} \mathrm{~s}^{-1}\right)$ & $\mathrm{k}_{\mathrm{off}}\left(\mathrm{s}^{-1}\right)$ & $\mathrm{K}_{\mathrm{D}}=\mathrm{k}_{\mathrm{off}} / \mathrm{k}_{\mathrm{on}}(\mathrm{M})$ & $\Delta \mathrm{G}^{*}\left(\mathrm{~kJ} \mathrm{~mol}^{-1}\right)$ \\
\hline \multirow[t]{2}{*}{ HP } & SDF- $1 \alpha$ & $5 \pm 1$ & $6.6 \pm 0.2 \times 10^{5}$ & $5.9 \pm 0.3 \times 10^{-4}$ & $9.0 \pm 0.5 \times 10^{-9}$ & $-45.90 \pm 0.06$ \\
\hline & IFN- $\gamma$ & $14 \pm 1$ & $6.7 \pm 0.3 \times 10^{5}$ & $7.4 \pm 0.2 \times 10^{-4}$ & $11.1 \pm 0.4 \times 10^{-9}$ & $-45.38 \pm 0.04$ \\
\hline \multirow[t]{2}{*}{ HS } & SDF-1 $\alpha$ & $5 \pm 1$ & $3.3 \pm 0.2 \times 10^{5}$ & $13.2 \pm 0.3 \times 10^{-4}$ & $4.0 \pm 0.2 \times 10^{-9}$ & $-47.91 \pm 0.05$ \\
\hline & $\mathrm{IFN}-\gamma$ & $12 \pm 3$ & $4.8 \pm 0.2 \times 10^{5}$ & $29.3 \pm 0.5 \times 10^{-4}$ & $6.1 \pm 0.2 \times 10^{-9}$ & $-46.87 \pm 0.03$ \\
\hline
\end{tabular}

$* \Delta \mathrm{G}=\mathrm{RT} \ln \mathrm{K}_{\mathrm{D}}$ where $\mathrm{R}$ is the gas constant $=8.3144621 \mathrm{~J} \mathrm{~mol}^{-1} \mathrm{~K}^{-1}$ and $\mathrm{T}$ is $298 \mathrm{~K}\left(25^{\circ} \mathrm{C}\right)$. Binding kinetics fitted using a 1:1 Langmuir model. Values were the average of 4 determinations 
Fig. 2 Surface molar density of GAG polysaccharides captured by immobilized proteins IFN- $\gamma$ (red), SDF-1 $\alpha$ (blue), and aprotinin (violet) according to the injected concentrations of a heparin (HP) and $\mathbf{b}$ heparan sulfate (HS). Error bars correspond to four different spots on the same biochip

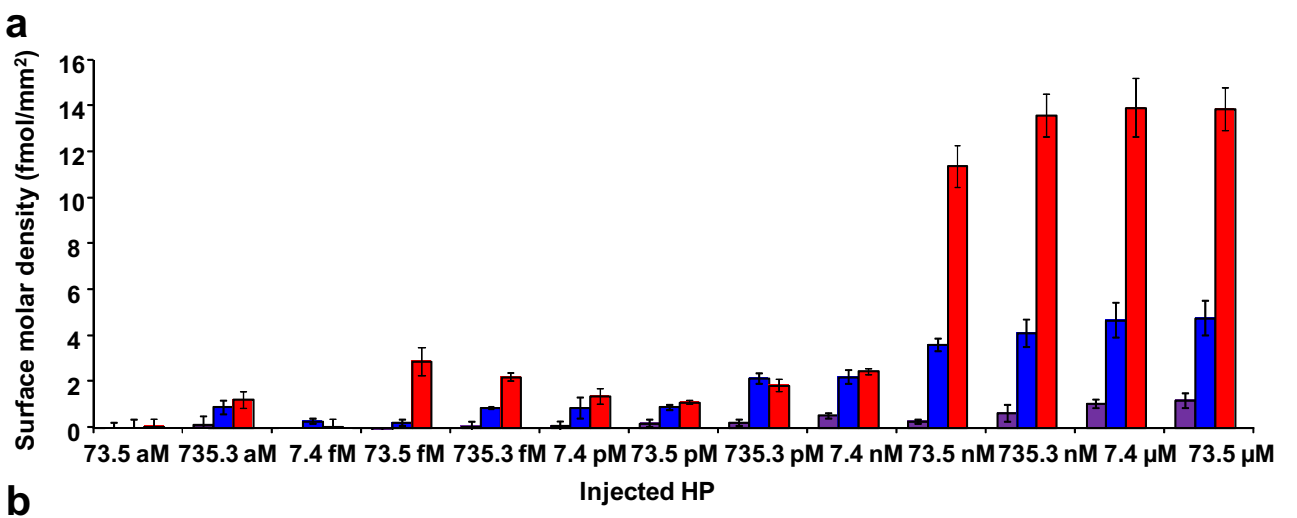

b

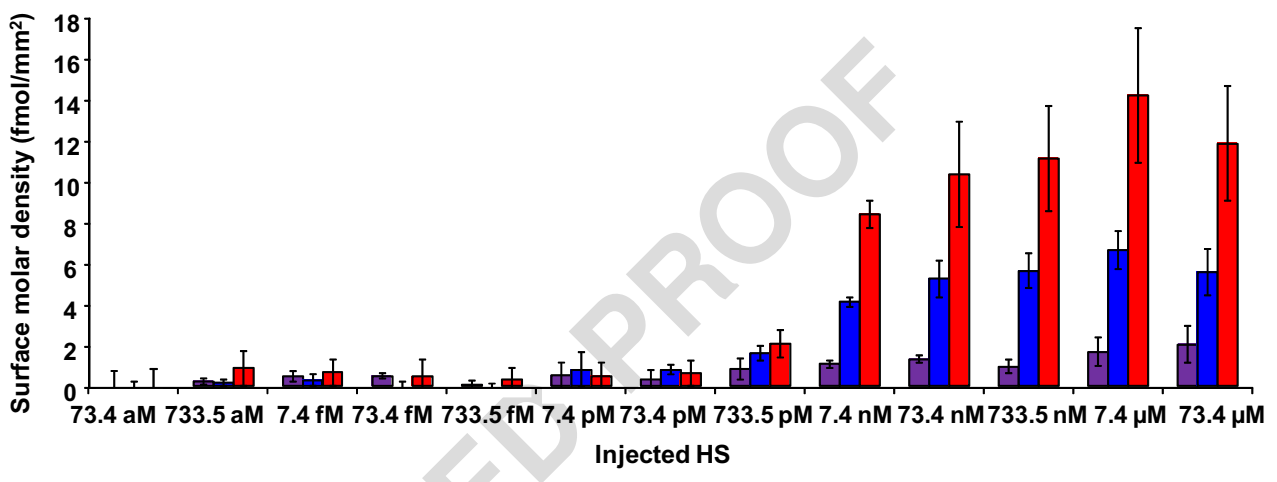

involved in the interactions of HS with various cytokines [21]. Accordingly, sensorgrams depicted a significant capture of GAGs molecules, which increased with rising concentrations of injected HPdp10, from $33.3 \mathrm{nM}$ to $333.3 \mu \mathrm{M}$ (Fig. 4c). The three cytokines showed similar off-rates, close to the $\mathrm{k}_{\text {off }}$ values obtained for HP/HS (21.2-30.6 $\times 10^{-4} \mathrm{~s}^{-1}$ versus 5.9$7.4 \times 10^{-4} / 13.2-29.3 \times 10^{-4} \mathrm{~s}^{-1}$ ), while their binding rates were slightly lower than that to HP/HS polysaccharides (Table 2). As a result, the increased $K_{D}$ values indicated a somewhat lowered affinity for HPdp10 in comparison with $\mathrm{HP} / \mathrm{HS}$ polysaccharides, but these values still remained in the sub-micromolar range (Table 2). Although the $\mathrm{k}_{\mathrm{off}}, \mathrm{k}_{\mathrm{on}}$, and $K_{D}$ values obtained for HPdp10 account for various dp10 chains in the decasaccharide preparation, they provide a meaningful averaged portray of the mixture.

An additional injection following the highest HPdp10 concentration $(333.3 \mu \mathrm{M})$ did not induce a further increase of reflectivity, indicating that all interaction sites were occupied and maximal interaction had been reached. It corresponded to a maximal surface density of several $\mathrm{fmol} / \mathrm{mm}^{2}$ of captured HPdp10 (Fig. 4c). The arrayed biochip surface was probed using MALDI-TOF MS to detect captured HPdp10. To allow detection of these high-polymerization-degree oligosaccharides at the highest sensitivity, MS analysis was carried out in linear mode.

Under these conditions, direct deposits of HPdp10 on the chip indicated that around 25 fmoles were required to yield a spectrum exhibiting ions ascribed to HPdp10 oligosaccharides (Fig. 5a).

It may explain that we were unable to detect any oligosaccharides on the MCP- 1 and SDF- $1 \alpha$ spots, given the lower amount of captured oligosaccharides. On the other hand, a wide range of ions ascribed to the HPdp10 oligosaccharides mixture was detected on IFN- $\gamma$ plots in agreement with about 25 fmol of captured oligosaccharides (Fig. 5b). When HPdp10 was directly deposited on the biochip, ions were detected along a Gaussian distribution from $\mathrm{m} / \mathrm{z} 1765.4$ to $\mathrm{m} / \mathrm{z} 2173.7$ and centered on $\mathrm{m} / \mathrm{z}$ 1867.5 (Fig. 5a). This ion distribution matches that of a decasaccharide population carrying from 1 to 5 sulfate groups and centered around $m / z$ 1800-1900 corresponding to disulfated species. By comparison, the spectrum obtained from IFN- $\gamma$ spots showed the selective enrichment of more sulfated oligosaccharides centered around $\mathrm{m} / \mathrm{z}$ 2100-2200. The absence of a single captured decasaccharide species shows that interaction between IFN- $\gamma$ and HPdp10 does not occur with only one given structure. IFN- $\gamma$, and possibly MCP-1 and SDF- $1 \alpha$, can thus bind several HPdp10 exhibiting various sulfation patterns. Even if the precise structural determinants involved in specific interactions could not be determined, our results indicate a preferential affinity for the more sulfated heparin chains. Nonetheless, the present results confirm the validity of the SPRi-MS coupling for on-chip analysis 
Surface plasmon resonance imaging coupled to on-chip mass spectrometry: a new tool to probe protein-GAG...

Fig. 3 Negative reflector MALDI-TOF spectra of on-chip depolymerized heparin captured by a IFN- $\gamma\left(14 \mathrm{fmol} / \mathrm{mm}^{2}\right)$, b $\mathrm{SDF}-1 \alpha\left(5 \mathrm{fmol} / \mathrm{mm}^{2}\right)$, and $\mathbf{c}$ aprotinin $\left(1 \mathrm{fmol} / \mathrm{mm}^{2}\right)$. All species are detected as $[\mathrm{M}-\mathrm{Na}]^{-}$ and size of the $\mathrm{dp}$ is indicated in blue, number of sulfates in red, and signal-to-noise ratio $(\mathrm{S} / \mathrm{N})$ on the HPdp2 with three sulfates is noted in the top right corner of each spectrum a

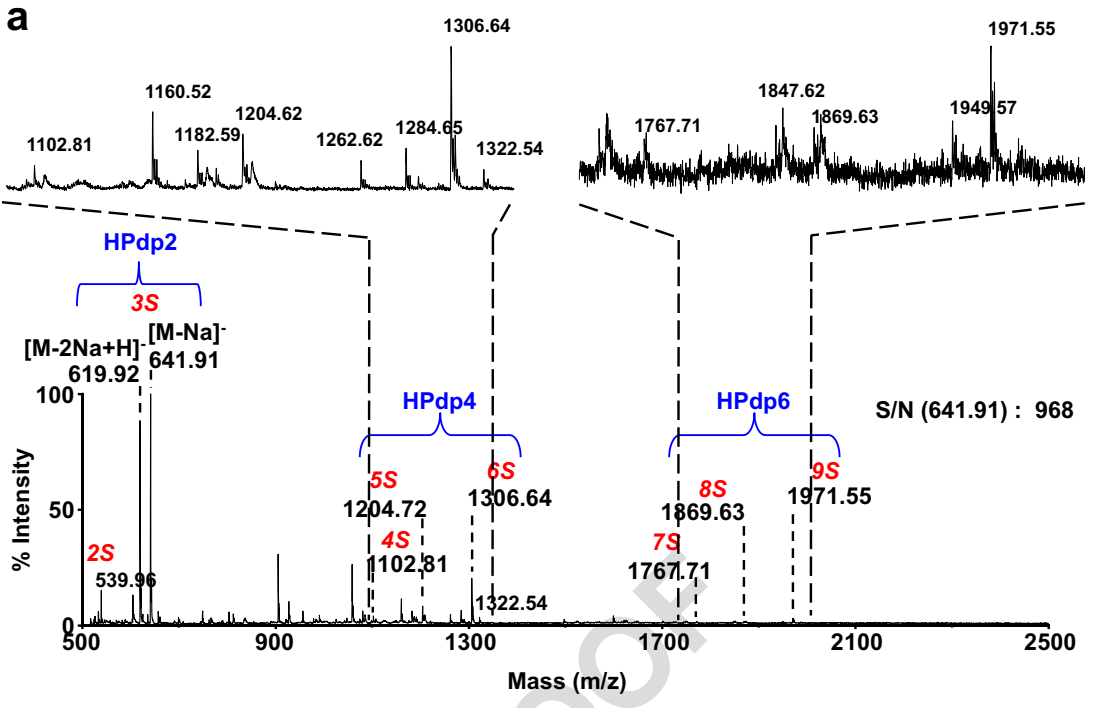

b
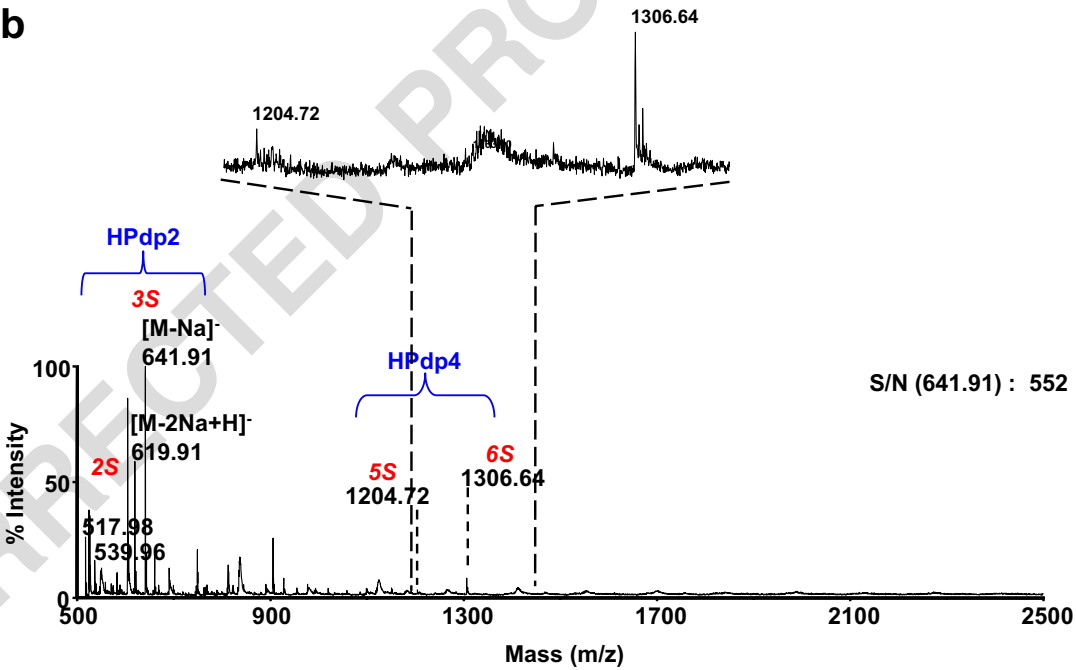

C

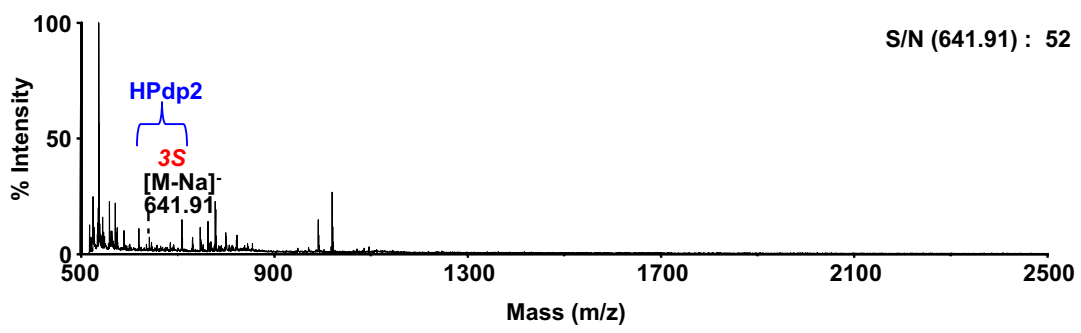

of GAG ligands after their capture by immobilized cytokines, and indicate that captured sulfated oligosaccharides of polymerization degrees higher than $\mathrm{dp} 2$ can be directly detected.

\section{Interaction of the synthetic pentasaccharide Fondaparinux on the cytokine SPR biochips}

To further exemplify the SPRi-MS coupling on cytokine biochip, an oligosaccharide with a well-defined sequence was used. For that purpose, we studied the interaction of the synthetic pentasaccharide Fondaparinux with the immobilized cytokines. This compound is the sole marketed synthetic GAG mimetic (Arixtra ${ }^{\circledR}$ ) used as an antithrombotic agent targeting antithrombin and thereby inhibiting proteases such as the activated factor $\mathrm{X}$ (FXa). This pentasaccharide has eight sulfate groups, including a rare 3-O sulfo group on the central glucosamine residue. Fondaparinux was designed to bind antithrombin with high affinity [52]. It can also bind MCP-1 [53, 54], but no data are available for SDF- $1 \alpha$ or IFN- $\gamma$. SPRi 
Fig. 4 a Surface-subtracted sensorgrams for the interaction between chemokines and a heparin decasaccharides mixture (HPdp10) injected at $1 \mathrm{mg} \mathrm{mL}^{-1}$ $(\approx 333.3 \mu \mathrm{M})$. Each sensorgram is the average of SPR measurements taken on four spots. $\mathbf{b}$ Corresponding real-time array imaging of the interaction between grafted chemokines and injected HPdp10 at $7 \mathrm{~min}$ in the aforementioned conditions. c Surface molar density progression of captured HPdp10. Error bars correspond to four different spots on the same biochip a

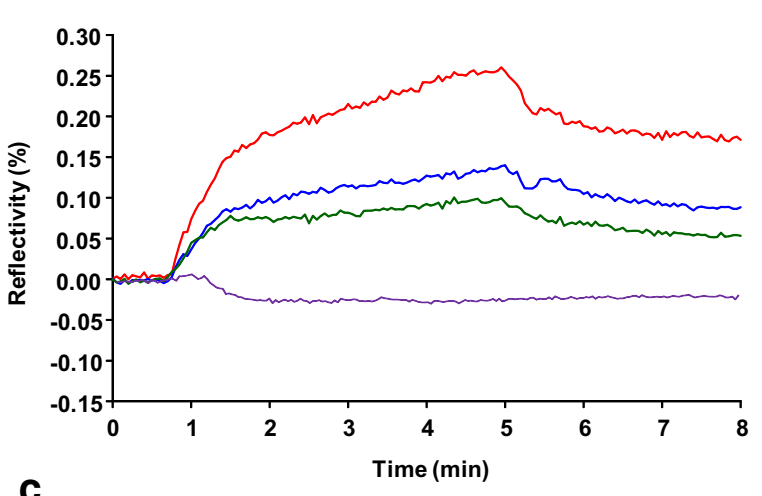

b

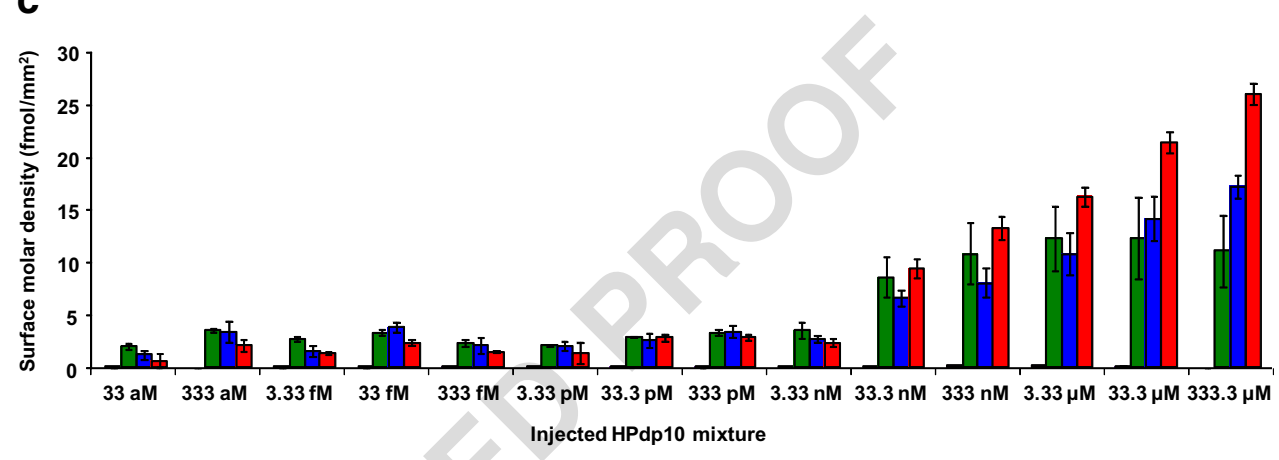

- IFN-Y - SDF-1a - MCP-1 - Aprotinin analysis confirmed the high affinity of MCP-1 for the synthetic pentasaccharide and also revealed a strong interaction with IFN- $\gamma$ and SDF- $1 \alpha$ (Fig. 6).

The obtained sensorgrams yielded nanomolar $\mathrm{K}_{\mathrm{D}}$ (Table 2) in the range of previously reported values for other highaffinity HP-binding proteins [4, 8, 47-49, 55-64]. The $\mathrm{K}_{\mathrm{D}}$ value for SDF-1 $\alpha$ was much lower than those determined for HPdp10, and almost in the same range as the $K_{D}$ values for HP/HS polysaccharides, underlining that a specific arrangement in a well-defined sequence, even in a short chain, can govern and induce the formation of a tight complex with SDF- $1 \alpha$. These productive sequences are likely sparse in HPdp10, which may explain the decreased affinity for this oligosaccharides mixture. In contrast, IFN- $\gamma$ showed a quite similar affinity for both HPdp10 and the synthetic pentasaccharide Fondaparinux, although somewhat higher for the pentasaccharide. This result suggests that IFN- $\gamma$ can form an affinity complex either with a short sequence comprising unique structural determinants, or with heterogeneous, but longer oligosaccharide sequences. Several fmol $\mathrm{mm}^{-2}$ of synthetic pentasaccharide were captured upon injection of increasing concentrations of Fondaparinux, leveling out at values ranging from 13 for SDF-1 $\alpha$ to 28 fmol $\mathrm{mm}^{-2}$ for IFN- $\gamma$ (Table 2). When 20 fmoles of pentasaccharide were directly spotted in the running buffer on the biochip, the pentasaccharide could be detected as an intact, fully sulfated species [M-Na] at $m / z$ 1703.8, in addition to ions corresponding to a pentasaccharide species with sulfate loss (-102 mass units) (Fig. 7a). The

Table 2 Kinetic and thermodynamic parameters of the interactions between cytokines and heparin-derived sulfated oligosaccharides

\begin{tabular}{lllllll}
\hline GAGs & Cytokine & Surface density $\left(\mathrm{fmol} / \mathrm{mm}^{2}\right)$ & $\mathrm{k}_{\text {on }}\left(\mathrm{M}^{-1} \mathrm{~s}^{-1}\right)$ & $\mathrm{k}_{\text {off }}\left(\mathrm{s}^{-1}\right)$ & $\mathrm{K}_{\mathrm{D}}=\mathrm{k}_{\text {off }} / \mathrm{k}_{\text {on }}(\mathrm{M})$ & $\Delta \mathrm{G}^{*}\left(\mathrm{~kJ} \mathrm{~mol}^{-1}\right)$ \\
\hline HPdp10 & SDF-1 $\alpha$ & $17 \pm 1$ & $2.3 \pm 0.4 \times 10^{4}$ & $30.6 \pm 0.5 \times 10^{-4}$ & $133 \pm 5 \times 10^{-9}$ & $-39.23 \pm 0.04$ \\
& MCP-1 & $11 \pm 3$ & $2.2 \pm 0.2 \times 10^{4}$ & $21.2 \pm 0.3 \times 10^{-4}$ & $96 \pm 4 \times 10^{-9}$ & $-40.04 \pm 0.04$ \\
& IFN- $\gamma$ & $25 \pm 1$ & $1.9 \pm 0.4 \times 10^{5}$ & $26.7 \pm 0.6 \times 10^{-4}$ & $14 \pm 1 \times 10^{-9}$ & $-44.81 \pm 0.07$ \\
Fondaparinux & SDF-1 $\alpha$ & $13 \pm 1$ & $5.2 \pm 0.3 \times 10^{5}$ & $15.6 \pm 0.5 \times 10^{-4}$ & $3.0 \pm 0.2 \times 10^{-9}$ & $-48.62 \pm 0.07$ \\
& MCP-1 & $17 \pm 5$ & $13.3 \pm 0.1 \times 10^{5}$ & $31.9 \pm 0.3 \times 10^{-4}$ & $2.4 \pm 0.1 \times 10^{-9}$ & $-49.20 \pm 0.04$ \\
& IFN- $\gamma$ & $28 \pm 5$ & $7.3 \pm 0.5 \times 10^{6}$ & $87.6 \pm 0.6 \times 10^{-4}$ & $1.2 \pm 0.1 \times 10^{-9}$ & $-50.89 \pm 0.08$
\end{tabular}

$* \Delta \mathrm{G}=\mathrm{RT} \ln \mathrm{K}_{\mathrm{D}}$ where $\mathrm{R}$ is the gas constant $=8.3144621 \mathrm{~J} \mathrm{~mol}^{-1} \mathrm{~K}^{-1}$ and $\mathrm{T}$ is $298 \mathrm{~K}\left(25^{\circ} \mathrm{C}\right)$. Binding kinetics fitted using a 1:1 Langmuir model. Values were the average of 4 determinations 
Surface plasmon resonance imaging coupled to on-chip mass spectrometry: a new tool to probe protein-GAG...

Fig. 5 Negative linear MALDITOF spectrum of HPdp10 mixture a directly deposited at 25 fmol on the chip and $\mathbf{b}$ after capture of $25 \mathrm{fmol} \mathrm{mm}^{-2}$ by IFN$\gamma$

Fig. 6 a Surface-subtracted sensorgrams for the interaction between chemokines and Fondaparinux injected at $1 \mathrm{mg} \mathrm{mL}^{-1}(\approx 579 \mu \mathrm{M})$. Each sensorgram results from the averaged SPR measurements on four spots. b Corresponding realtime array imaging of the interaction between grafted cytokines and injected Fondaparinux at $7 \mathrm{~min}$ in the aforementioned conditions. $\mathbf{c}$ Surface molar density progression of captured Fondaparinux. Error bars correspond to four different spots on the same biochip
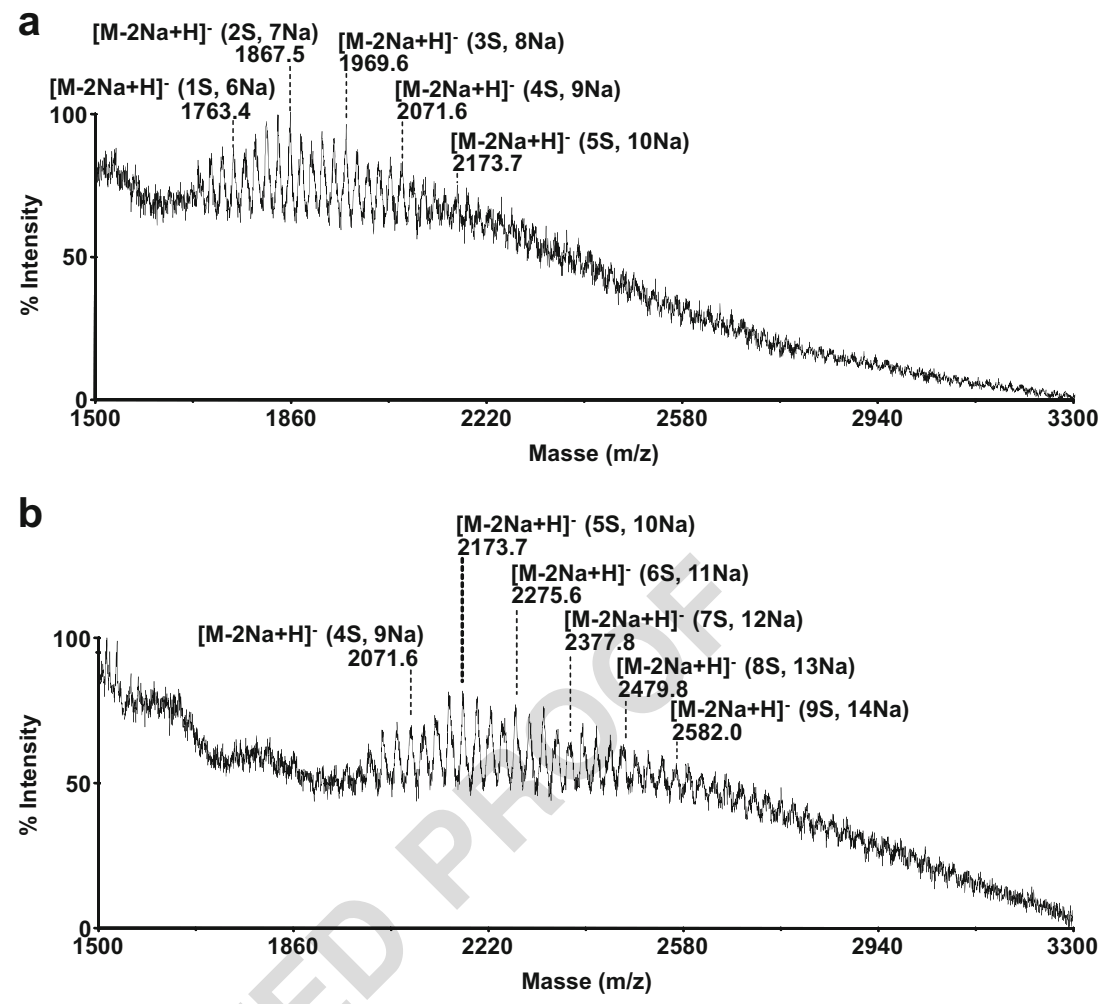

a

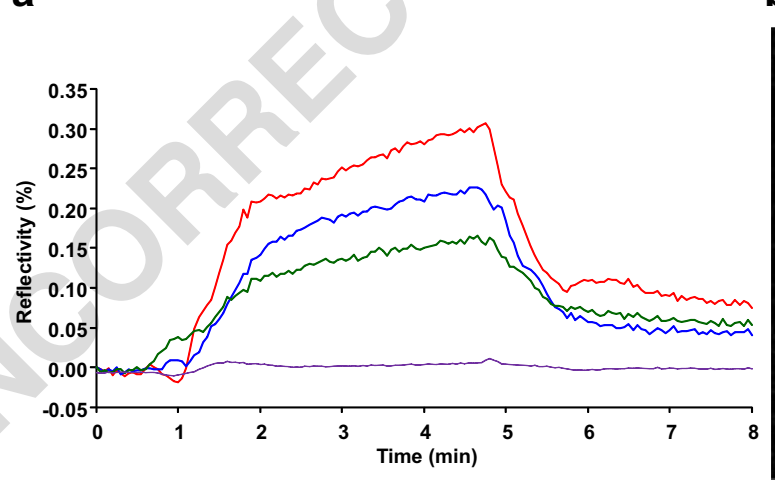

C

b
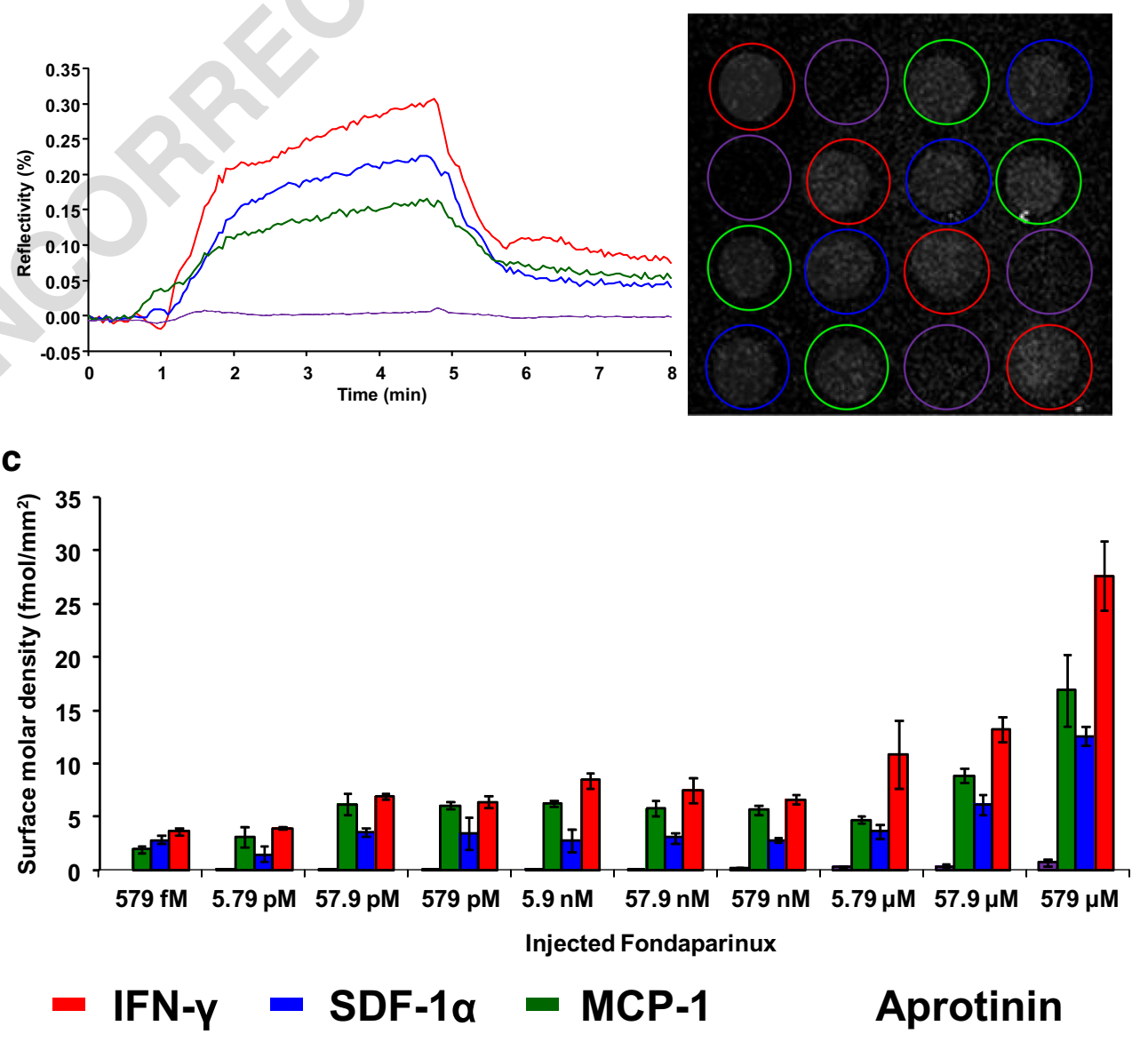

Aprotinin 


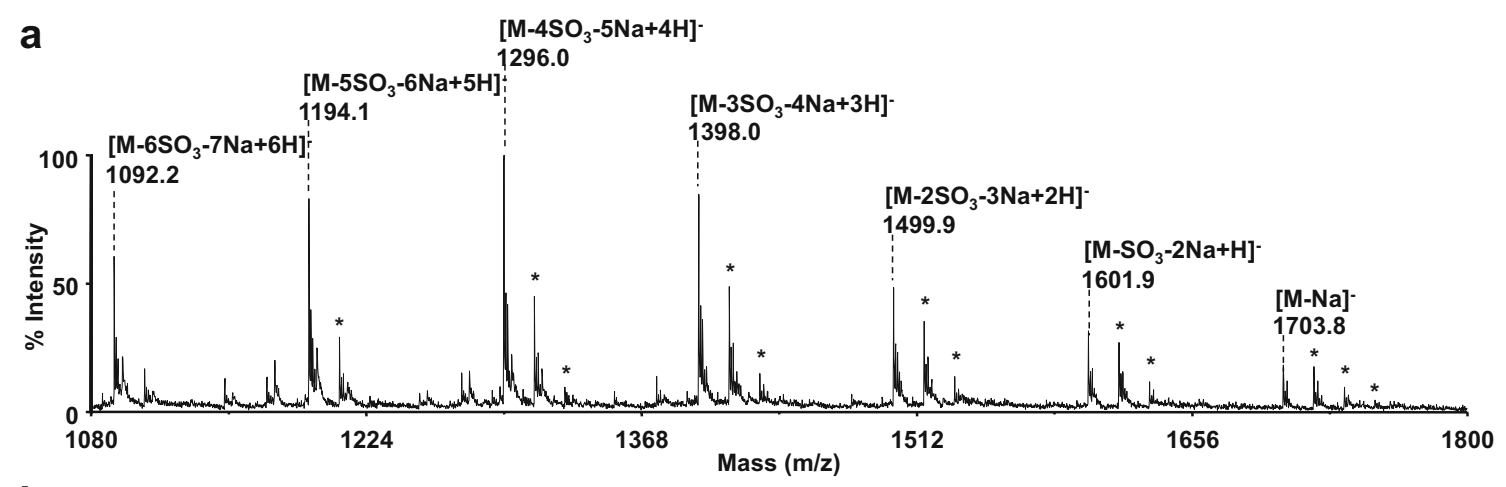

b

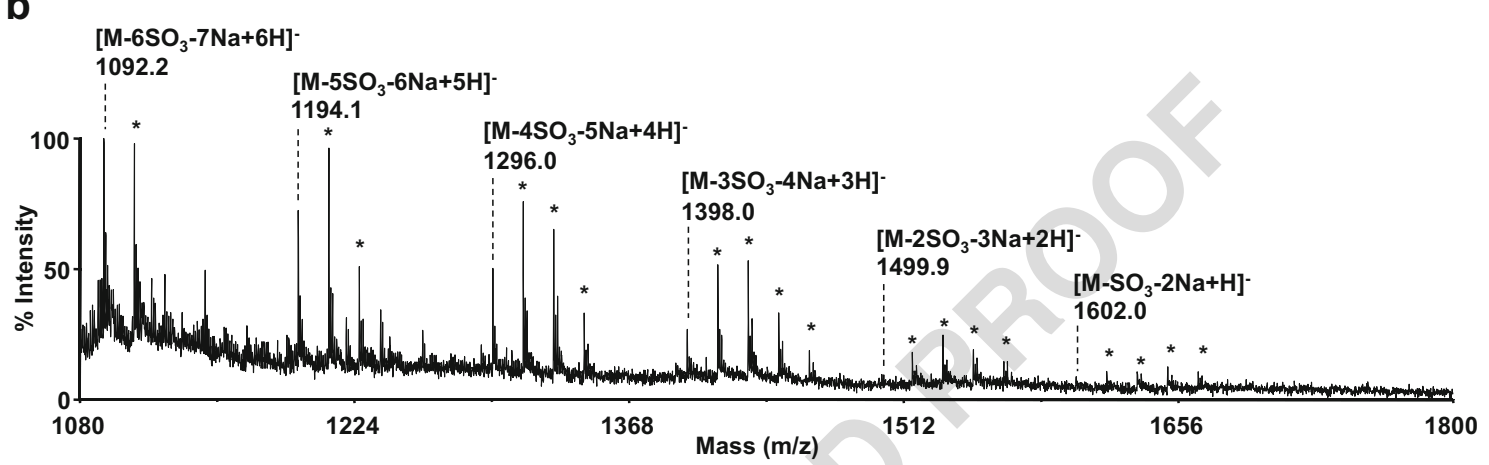

C

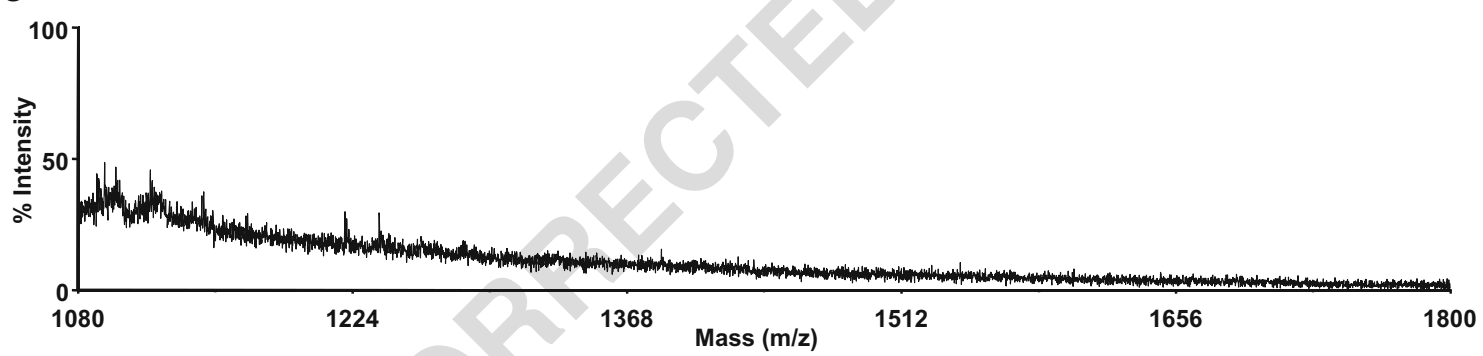

d

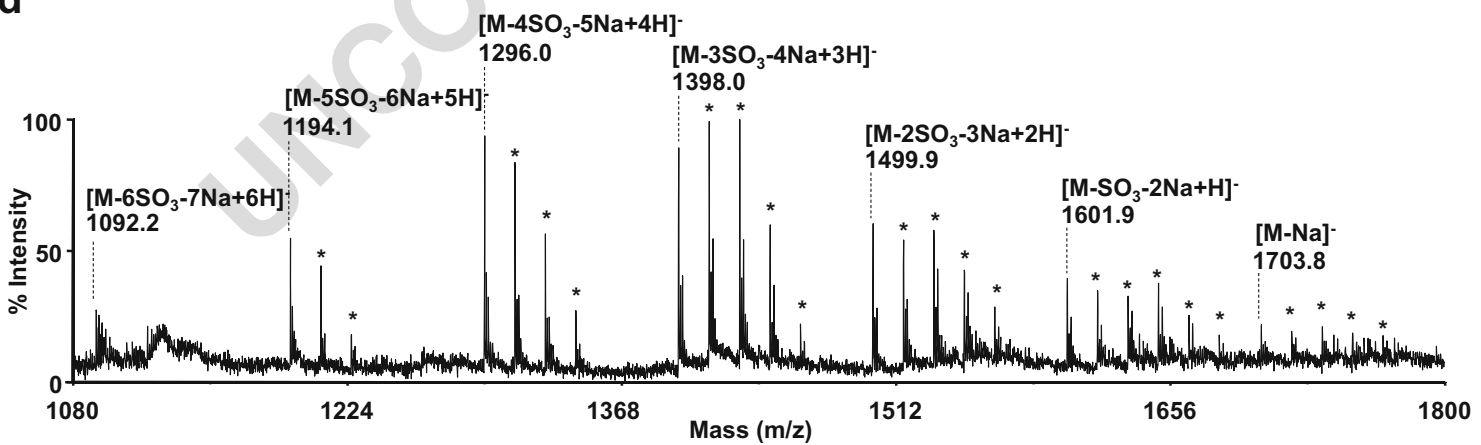

Fig. 7 Negative reflector MALDI-TOF spectra of Fondaparinux a directly deposited at 20 fmoles on the chip and after captures by b MCP-1, $\mathbf{c}$ SDF-1 $\alpha$, and d IFN- $\gamma$ after injection of $579 \mu \mathrm{M}$ Fondaparinux. Asterisks correspond to $\mathrm{Na}^{+} / \mathrm{K}^{+}$exchanges

signal-to-noise ratio of mass spectra gradually declined from the IFN- $\gamma$ to the MCP- 1 and SDF- $1 \alpha$ spots, in parallel to a concomitant decrease in the surface density $(28,17$, and 13 $\mathrm{fmol} / \mathrm{mm}^{2}$, respectively). Intact or partially desulfated pentasaccharide species were not detected on the SDF- $1 \alpha$ spots (Fig. 7c), likely due to the lower captured amount (13 fmol $\mathrm{mm}^{-2}$ ). On the other hand, the intact pentasaccharide $[\mathrm{M}-\mathrm{Na}]^{-}$ was observed on the IFN- $\gamma$ spots (Fig. 7d), while only partially sulfated species with 1 to 6 sulfate losses were detected on the MCP-1 spots (Fig. 7b). The non-detection of intact pentasaccharide on MCP-1 spots can be due to an insufficient amount captured and less efficient energy dissipation during laser shots while soft ionic liquid matrix was used. The on-chip MS detection was easier for Fondaparinux than for HPdp10, although both were captured at similar surface densities. This difference highlights that, in addition to the low 
amount and the size of oligosaccharides, the heterogeneity of the oligosaccharide mixture can be also an important limiting factor for the MALDI-TOF analysis.

\section{Conclusion}

The hyphenation of SPR with MS relies on two wellestablished stand-alone methods that enable the analysis of biomolecular interactions and biostructural characterization, respectively. We have previously developed the functionalization of SPRi biochips with a self-assembled monolayer of short poly(ethyleneoxide) chains carrying a terminal NHS group that is well-suited for SPRi-MS coupling, and useful for efficient on-chip MALDI MS detection. SPRiMS coupling having been initially applied to the study of protein-protein interactions, this study significantly extends proof of concept to the analysis of protein-carbohydrate interactions. This study reports for the first time the implementation of SPRi-MS coupling analysis of interactions between GAGs and relevant cytokines, showing a new road for probing biomolecular interactions involving GAGs. This approach made it possible to detect and quantify the formation of complexes between HP and HS oligo/polysaccharides and immobilized chemokines, and shows its potential to achieve the direct on-chip MS detection of GAG ligands through their selective capture. As in proteomics, we demonstrated the feasibility of performing an efficient on-chip enzymatic digestion of captured polysaccharides for easier and more detailed MS identification. In this study, SPRi-MS analysis was conducted on manually deposited 12 or 16 spots per biochip, and work is in progress to use similar chips with an automatic arrayer allowing a more reproducible and higher density spotting. Still, the limitations of the SPRi-MS coupling identified in this study require further efforts. The amounts of captured GAG molecules are enough for SPRi detection but are too low in some case for an easy MS detection. Modifications of the surface self-assembled monolayer and a controlled orientation of the immobilized protein are currently under investigation to get a higher density of grafted chemokine. The partial loss of sulfate that sometime occurs upon laser irradiation may prevent the determination of the optimal sulfation level preferred by each chemokine. Probing the biochip surface with a softer ionization method like DESI coupled to LTQ-Orbitrap will be an attractive alternative $[65,66]$. The GAGomics field still requires new analytical tools for further study of proteinGAG interactions and for the discovery of potential compounds targeting these complexes. All the analytical features of the SPRi-MS coupling reported here, including multiplexed detection of interaction partners, specific capture of GAG ligands, and on-chip MS characterization thus appear very promising for GAGomics and more largely in glycobiology.

\section{Compliance with ethical standards}

Conflict of interest The authors declare that there are no conflicts of interest.

\section{References}

1. Bishop JR, Schuksz M, Esko JD. Heparan sulphate proteoglycans fine-tune mammalian physiology. Nature. 2007;446:1030-7.

2. Linhardt RJ, Toida T. Role of glycosaminoglycans in cellular communication. Acc Chem Res. 2004;37:431-8.

3. Sasisekharan R, Raman R, Prabhakar V. Glycomics approach to structure-function relationships of glycosaminoglycans. Annu Rev Biomed Eng. 2006;8:181-31.

4. Capila I, Linhardt RJ. Heparin-protein interactions. Angew Chem Int Ed. 2002;41:390-12.

5. Spillmann D, Lindahl U. Glycosaminoglycan-protein interactions: a question of specificity. Curr Opin Struct Biol. 1994;4:677-82.

6. Ricard-Blum S. Protein-glycosaminoglycan interaction networks: focus on heparan sulfate. Perspect Sci. 2017;11:62-9.

7. Rogers CJ, Clark PM, Tully SE, Abrol R, Garcia KC, Goddard WA 3rd, et al. Elucidating glycosaminoglycan-protein-protein interactions using carbohydrate microarray and computational approaches. Proc Natl Acad Sci U S A. 2011;108:9747-52.

8. Saesen E, Sarrazin S, Laguri C, Sadir R, Maurin D, Thomas A, et al. Insights into the mechanism by which interferon- $\gamma$ basic amino acid clusters mediate protein binding to heparan sulfate. J Am Chem Soc. 2013;135:9384-90.

9. Soares da Costa D, Reis RL, Pashkuleva I. Sulfation of glycosaminoglycans and its implications in human health and disorders. Annu Rev Biomed Eng. 2017;19:1-26.

10. Gandhi NS, Mancera RL. The structure of glycosaminoglycans and their interactions with proteins. Chem Biol Drug Des. 2008;72: 455-82.

11. Kuschert GSV, Coulin F, Power CA, Proudfoot AEI, Hubbard RE, Hoogewerf AJ, et al. Glycosaminoglycans interact selectively with chemokines and modulate receptor binding and cellular responses. Biochemistry. 1999;38:12959-68.

12. Rusnati M, Coltrini D, Oreste P, Zoppetti G, Albini A, Noonan D, et al. Interaction of HIV-1 tat protein with heparin: role of the backbone structure, sulfation, and size. J Biol Chem. 1997;272:1131320.

13. de Paz JL, Seeberger PH. Deciphering the glycosaminoglycan code with the help of microarrays. Mol BioSyst. 2008;4:707-11.

14. Gama CI, Hsieh-Wilson LC. Chemical approaches to deciphering the glycosaminoglycan code. Curr Opin Chem Biol. 2005;9:60919.

15. Gama CI, Tully SE, Sotogaku N, Clark PM, Rawat M, Vaidehi N, et al. Sulfation patterns of glycosaminoglycans encode molecular recognition and activity. Nat Chem Biol. 2006;2:467-73.

16. Faham S, Hileman RE, Fromm JR, Linhardt RJ, Rees DC. Heparin structure and interactions with basic fibroblast growth factor. Science. 1996;271:1116-20.

17. Gallagher JT. Heparan sulfate: growth control with a restricted sequence menu. J Clin Invest. 2001;108:357-61.

18. Khan S, Gor J, Mulloy B, Perkins SJ. Semi-rigid solution structures of heparin by constrained X-ray scattering modelling: new insight into heparin-protein complexes. J Mol Biol. 2010;395:504-21.

19. Khan S, Rodriguez E, Patel R, Gor J, Mulloy B, Perkins SJ. The solution structure of heparan sulphate differs from that of heparin: implications for function. J Biol Chem. 2013;288:27737-51.

20. Li W, Johnson DJD, Esmon CT, Huntington JA. Structure of the antithrombin-thrombin-heparin ternary complex reveals the 
antithrombotic mechanism of heparin. Nat Struct Mol Biol. 2004;11:857-62.

21. Lubineau A, Lortat-Jacob H, Gavard O, Sarrazin S, Bonnaffe D. Synthesis of tailor-made glycoconjugate mimetics of heparan sulfate that bind IFN-gamma in the nanomolar range. Chem.-Eur. J. 2004;10:4265-82.

22. Venkataraman G, Raman R, Sasisekharan V, Sasisekharan R. Molecular characteristics of fibroblast growth factor-fibroblast growth factor receptor-heparin-like glycosaminoglycan complex. Proc Natl Acad Sci U S A. 1999;96:3658-63.

23. Karamanos NK, Tzanakakis GN. Glycosaminoglycans: from "cellular glue" to novel therapeutical agents. Curr Opin Pharmacol. 2012;12:220-2.

24. Volpi N. Therapeutic applications of glycosaminoglycans. Curr Med Chem. 2006;13:1799-810.

25. Esko JD, Selleck SB. Order out of chaos: assembly of ligand binding sites in heparan sulfate. Annu Rev Biochem. 2002;71:435-71.

26. Zaia J. On-line separations combined with MS for analysis of glycosaminoglycans. Mass Spectrom Rev. 2009;28:254-72.

27. Zaia J. Glycosaminoglycan glycomics using mass spectrometry. Mol Cell Proteomics. 2013;12:885-92.

28. Fermas S, Gonnet F, Sutton A, Charnaux N, Mulloy B, Du Y, et al. Sulfated oligosaccharides (heparin and fucoidan) binding and dimerization of stromal cell-derived factor-1 (SDF-1/CXCL 12) are coupled as evidenced by affinity CE-MS analysis. Glycobiology. 2008;18:1054-64.

29. Fermas S, Gonnet F, Varenne A, Gareil P, Daniel R. Frontal analysis capillary electrophoresis hyphenated to electrospray ionization mass spectrometry for the characterization of the antithrombin/ heparin pentasaccharide complex. Anal Chem. 2007;79:4987-93.

30. Fukui S, Feizi T, Fau-Galustian C, Galustian C, Fau-Lawson AM, Lawson AM, et al. Oligosaccharide microarrays for highthroughput detection and specificity assignments of carbohydrateprotein interactions. Nat Biotechnol. 2002;20:1011-7.

31. Gray CJ, Sánchez-Ruíz A, Šardzíková I, Ahmed YA, Miller RL, Reyes Martinez JE, et al. Label-free discovery array platform for the characterization of glycan binding proteins and glycoproteins. Anal Chem. 2017;89:4444-51.

32. Wang D, Liu S, Fau-Trummer BJ, Trummer BJ, Fau-Deng C, Deng $\mathrm{C}$, et al. Carbohydrate microarrays for the recognition of crossreactive molecular markers of microbes and host cells. Nat Biotechnol. 2002;20:275-81.

33. Homola J. Surface plasmon resonance sensors for detection of chemical and biological species. Chem Rev. 2008;108:462-93.

34. Nelson RW, Krone JR, Jansson O. Surface plasmon resonance biomolecular interaction analysis mass spectrometry. 1. Chip-Based Analysis. Anal Chem. 1997;69:4363-8.

35. Nelson RW, Nedelkov D, Tubbs KA. Biomolecular interaction analysis mass spectometry. BIA/MS can detect and characterize protiens in complex biological fluids at the low- to subfemtomole level. Anal Chem. 2000;72:404A-11A.

36. Bellon S, Buchmann W, Gonnet F, Jarroux N, Anger-Leroy M, Guillonneau $\mathrm{F}$, et al. Hyphenation of surface plasmon resonance imaging to matrix-assisted laser desorption ionization mass spectrometry by on-chip mass spectrometry and tandem mass spectrometry analysis. Anal Chem. 2009;81:7695-02.

37. Musso J, Buchmann W, Gonnet F, Jarroux N, Bellon S, Frydman C, et al. Biomarkers probed in saliva by surface plasmon resonance imaging coupled to matrix-assisted laser desorption/ionization mass spectrometry in array format. Anal Bioanal Chem. 2014;407:128594.

38. Remy-Martin F, El Osta M, Lucchi G, Zeggari R, Leblois T, Bellon $\mathrm{S}$, et al. Surface plasmon resonance imaging in arrays coupled with mass spectrometry (SUPRA-MS): proof of concept of on-chip characterization of a potential breast cancer marker in human plasma. Anal Bioanal Chem. 2012;404:423-32.
39. Anders U, Schaefer JV, Hibti F-E, Frydman C, Suckau D, Plückthun A, et al. SPRi-MALDI MS: characterization and identification of a kinase from cell lysate by specific interaction with different designed ankyrin repeat proteins. Anal Bioanal Chem. 2017:409:1827-36.

40. Sarrazin S, Bonnaffe D, Lubineau A, Lortat-Jacob H. Heparan sulfate mimicry: a synthetic glycoconjugate that recognizes the heparin binding domain of interferon-gamma inhibits the cytokine activity. J Biol Chem. 2005;280:37558-64.

41. Zhao H, Brown Patrick H, Schuck P. On the distribution of protein refractive index increments. Biophys J. 2011;100:2309-17.

42. Tumolo T, Angnes L, Baptista MS. Determination of the refractive index increment $(\mathrm{dn} / \mathrm{dc})$ of molecule and macromolecule solutions by surface plasmon resonance. Anal Biochem. 2004;333:273-9.

43. Przybylski C, Gonnet F, Bonnaffe D, Hersant Y, Lortat-Jacob H, Daniel R. HABA-based ionic liquid matrices for UV-MALDI-MS analysis of heparin and heparan sulfate oligosaccharides. Glycobiology. 2010;20:224-34.

44. Ropartz D, E BP, Przybylski C, Gonnet F, Daniel R, Fer M, et al. Performance evaluation on a wide set of matrix-assisted laser desorption ionization matrices for the detection of oligosaccharides in a high-throughput mass spectrometric screening of carbohydrate depolymerizing enzymes. Rapid Commun Mass Spectrom. 2011;25:2059-70.

45. Seffouh A, Milz F, Przybylski C, Laguri C, Oosterhof A, Bourcier $\mathrm{S}$, et al. HSulf sulfatases catalyze processive and oriented 6-Odesulfation of heparan sulfate that differentially regulates fibroblast growth factor activity. FASEB J. 2013;27:2431-9.

46. Przybylski C, Mokaddem M, Prull-Janssen M, Saesen E, LortatJacob $\mathrm{H}$, Gonnet F, et al. On-line capillary isoelectric focusing hyphenated to native electrospray ionization mass spectrometry for the characterization of interferon-[gamma] and variants. Analyst. 2015;140:543-50.

47. Lortat-Jacob H, Kleinman HK, Grimaud JA. High-affinity binding of interferon-gamma to a basement membrane complex (matrigel). J Clin Invest. 1991;87:878-83.

48. Friand V, Haddad O, Papy-Garcia D, Hlawaty H, Vassy R, HammaKourbali Y, et al. Glycosaminoglycan mimetics inhibit SDF-1/ CXCL12-mediated migration and invasion of human hepatoma cells. Glycobiology. 2009;19:1511-24.

49. Ziarek JJ, Veldkamp CT, Zhang F, Murray NJ, Kartz GA, Liang X, et al. Heparin oligosaccharides inhibit chemokine (CXC motif) ligand 12 (CXCL12) cardioprotection by binding orthogonal to the dimerization interface, promoting oligomerization, and competing with the chemokine (CXC motif) receptor 4 (CXCR4) N terminus. J Biol Chem. 2013;288:737-46.

50. Sadir R, Baleux F, Grosdidier A, Imberty A, Lortat-Jacob H. Characterization of the stromal cell-derived factor-1-heparin complex. J Biol Chem. 2001;276:8288-96.

51. Xiao Z, Zhao W, Yang B, Zhang Z, Guan H, Linhardt RJ Heparinase 1 selectivity for the 3,6-di-O-sulfo-2-deoxy-2sulfamido- $\alpha$-D-glucopyranose $(1,4) 2$-O-sulfo- $\alpha$-Lidopyranosyluronic acid (GlcNS3S6S-IdoA2S) linkages. Glycobiology. 2011;21:13-22.

52. Guerrini M, Guglieri S, Casu B, Torri G, Mourier P, Boudier C, et al. Antithrombin-binding octasaccharides and role of extensions of the active pentasaccharide sequence in the specificity and strength of interaction. Evidence for very high affinity induced by an unusual glucuronic acid residue. J Biol Chem. 2008;283:2666275.

53. Schenauer MR, Leary JA. An ion mobility-mass spectrometry investigation of monocyte chemoattractant protein-1. Int J Mass Spectrom. 2009;287:70-6.

54. Crown SE, Yu Y, Sweeney MD, Leary JA, Handel TM. Heterodimerization of CCR2 chemokines and regulation by glycosaminoglycan binding. J Biol Chem. 2006;281:25438-46. 
55. Lortat-Jacob H, Baltzer F, Grimaud J-A. Heparin decreases the blood clearance of interferon- $\gamma$ and increases its activity by limiting the processing of its carboxyl-terminal sequence. J Biol Chem. 1996;271:16139-43.

56. Lortat-Jacob H, Brisson C, Guerret S, Morel G. Non-receptormediated tissue localization of human interferon- $\gamma$ : role of heparan sulfate/heparin like moelcules. Cytokines. 1996;8:557-66.

57. Sadir R, Forest E, Lortat-Jacob H. The heparan sulfate binding sequence of interferon-gamma increased the on rate of the interferon-gamma-interferon-gamma receptor complex formation. J Biol Chem. 1998;273:10919-25.

58. Camejo EH, Rosengren B, Camejo G, Sartipy P, Fager G, Bondjers G. Interferon gamma binds to extracellular matrix chondroitinsulfate proteoglycans, thus enhancing its cellular response. Arterioscler Thromb Vasc Biol. 1995;15:1456-65.

59. Lortat-Jacob H, Grimaud JA. Binding of interferon-gamma to heparan sulfate is restricted to the heparin-like domains and involves carboxylic-but not N-sulfated-groups. Biochim Biophys Acta, Gen Subj. 1992;1117:126-30.

60. Lortat-Jacob H, Grimaud JA. Interferon-gamma C-terminal function: new working hypothesis. Heparan sulfate and heparin, new targets for IFN-gamma, protect, relax the cytokine and regulate its activity. Cell Mol Biol. 1991;37:253-60.

61. Vanhaverbeke C, Simorre JP, Sadir R, Gans P, Lortat-Jacob H. NMR characterization of the interaction between the C-terminal domain of interferon-gamma and heparin-derived oligosaccharides. $\quad 754$ Biochem J. 2004;384:93-9.

62. Lortat-Jacob H, Grimaud J-A. Interferon- $\gamma$ binds to heparan sulfate by a cluster of amino acids located in the C-terminal part of the molecule. FEBS Lett. 1991;280:152-4.

63. Hoogewerf AJ, Kuschert GSV, Proudfoot AEI, Borlat F, ClarkLewis I, Power CA, et al. Glycosaminoglycans mediate cell surface oligomerization of chemokines. Biochemistry. 1997;36:13570-8.

64. Chakravarty L, Rogers L, Quach T, Breckenridge S, Kolattukudy PE. Lysine 58 and histidine 66 at the C-terminal alpha-helix of monocyte chemoattractant protein-1 are essential for glycosaminoglycan binding. J Biol Chem. 1998;273:29641-7.

65. Przybylski C, Gonnet F, Hersant Y, Bonnaffe D, Lortat-Jacob H, 766 Daniel R. Desorption electrospray ionization mass spectrometry of 767 glycosaminoglycans and their protein noncovalent complex. Anal 768 Chem. 2010;82:9225-33.

66. Przybylski C, Gonnet F, Buchmann W, Daniel R. Critical parameters for the analysis of anionic oligosaccharides by desorption electrospray ionization mass spectrometry. J Mass Spectrom. 2012;47:1047-58.

Publisher's note Springer Nature remains neutral with regard to jurisdictional claims in published maps and institutional affiliations. 